\title{
MULHERES INDÍGENAS E SAÚDE: UMA ANÁLISE DO DISCURSO CIENTIIFICO À LUZ DA CRÍTICA FEMINISTA E DOS ESTUDOS DE GÊNERO
}

\section{Luciana Patrícia Zucco'}

\section{Stephany Yolanda Ril ${ }^{2}$}

Resumo: Este artigo apresenta uma análise do discurso científico sobre a saúde da mulher indigena, com enfoque na saúde sexual e reprodutiva. Nossa proposta foi averiguar, a partir dos estudos feministas e de gênero no campo da saúde, como as mulheres indígenas são representadas. Para tanto, realizamos levantamento na biblioteca SciELO e análise dos dados. Os resultados indicam produção diminuta tanto de estudos referentes à temática, quanto de trabalhos voltados para a dimensão subjetiva e cultural. A compreensão de raça e etnia como sinônimos atravessa a discussão, havendo predominância de estudos epidemiológicos e o contínuo apagamento de experiências das mulheres indígenas. Palavras-chaves: discurso científico; mulheres indígenas; saúde sexual e reprodutiva.

Abstract: This article presents an analysis of the scientific discourse on the health of indigenous women, with focus on sexual and reproductive health. Our proposal was to ascertain, from feminist and gender studies in the field of Health, how indigenous women are represented. For that, we performed a survey in the SciELO library and data analysis. The results indicate a small production of both studies related to the theme, as well as works focusing on the subjective and cultural dimension. The understanding of race and ethnicity as synonyms crosses the discussion, with predominance of epidemiological studies and the continuous erasure of experiences of indigenous women. Keywords: scientific discourse; indigenous women; sexual and reproductive health.

\footnotetext{
1 Doutora em Ciências da Saúde pelo Programa de Pós Graduação em Saúde da Criança e da Mulher do IFF, Fundação Oswaldo Cruz (FIOCRUZ, Brasil). Professora da Universidade Federal de Santa Catarina. E-mail: Ipzucco@uol. com.br.

2 Assistente Social. Integrante do Núcleo de Estudos em Serviço Social e Relações de Gênero da UFSC (Brasil). E-mail: stephanyril.ss@gmail.com.
} 


\section{Introdução}

A crítica feminista (HARAWAY, 1995; HARDING, 1993 e 2002) aponta que as teorias tradicionais, fundamentadas nos paradigmas da objetividade e da neutralidade, têm sido empregadas: 1 ) impedindo que as mulheres sejam sujeitas/ agentes do conhecimento; 2 ) impossibilitando a compreensão de que as atividades masculinas não equivalem à "humanidade" e são historicamente determinadas pelo gênero. Nesse sentido, Haraway (1993) sinaliza que o discurso científico ocidental, em conformidade aos demais conhecimentos, reproduz tais tendências e é produzido socialmente, sendo permeado por relações de poder.

entendimento de que a história da ciência é essencialmente masculina e, deste modo, escrita a partir da perspectiva dos homens de classe, raça ou etnia dominantes, evidenciou a premência de teorias que visibilizem as histórias das mulheres. Louro (1996) narra que o processo de inclusão do debate de gênero na construção dos saberes ocidentais ocorreu, primeiramente, no campo universitário. Este processo contribuiu para deslocar a mulher das notas de rodapé, "onde ela era entendida como um desvio da norma masculina ou como minoria" (LOURO, 1996, p. 08), para transformá-la em sujeito-objeto científico. A emergência do conceito de gênero, por sua vez, potencializou os estudos sobre os processos sociais e relacionais de formação das feminilidades e das masculinidades, instituindo a relação sujeito-sujeito.

No campo da saúde, inspirando-se nos estudos de gênero, a Política Nacional de Atenção Integral à Saúde da Mulher (PNAISM, 2004) prevê a necessidade de incorporar as demandas específicas das diferentes faixas etárias e dos distintos grupos populacionais (mulheres negras, indígenas, no climatério, adolescentes, lésbicas, entre outras), com o objetivo de contemplar todos os ciclos de vida da mulher. Apesar do reconhecido esforço da Política em não universalizar a categoria mulher, nos parece que ainda persiste a tendência ao apagamento das diferenças existentes entre os sujeitos envolvidos, não só na prática cotidiana das instituições de saúde pública, mas também na produção científica no campo da saúde.

Este artigo apresenta uma análise do discurso científico sobre a saúde da mulher indígena, com especial enfoque na saúde sexual e reprodutiva. Nossa proposta foi 
averiguar, a partir dos estudos feministas e de gênero no campo da saúde, como as mulheres indígenas são representadas. Partimos da hipótese de que os processos de saúde e de adoecimento das mulheres indigenas figuram nessas publicações a partir de leituras epidemiológicas, sendo suas experiências e histórias de vida como mulheres e indígenas secundarizadas ou discutidas de maneira genérica, reafirmando o olhar universalista para as mesmas. Tal tendência desconsidera as especificidades previstas na PNAISM, enfaticamente trabalhadas nos estudos feministas e de gênero, e necessárias para a compreensão da forma como as mulheres indigenas significam suas vivências, adoecimento e cuidado com a saúde sexual e reprodutiva.

interesse para a realização do presente estudo surgiu da experiência de estágio na Unidade de Internação Pediátrica, como assistente social e residente da ênfase de Saúde da Mulher e da Criança da Residência Integrada Multiprofissional em Saúde, do Hospital Universitário Professor Polydoro Ernani de São Thiago (HU/UFSC). O enfoque na saúde sexual e saúde reprodutiva resultou da aproximação com essa área, devido aos atendimentos às mulheres gestantes de alto-risco e mulheres mães que acompanham suas/ seus recém-nascidas/os na unidade neonatal.

$\mathrm{Na}$ ocasião, foram realizados atendimentos às mulheres indígenas mães que acompanharam suas filhas no período de internação hospitalar. Chamou a atenção o receio que a equipe multiprofissional apresentava no manejo ${ }^{3}$ com a pessoa indigena, além dos comentários depreciativos (como por exemplo, "indiazinha"), o não reconhecimento delas como sujeito e a anulação da autonomia dessas mulheres mães.

Vale ressaltar que, de maneira geral, os familiares de crianças internadas possuem autonomia limitada no território hospitalar, resultante de uma cultura biomédica (CARAPINHEIRO, 1988; HYGINO, 2017). Historicamente, a prática biomédica impõem uma hierarquização na qual o/a médico/a é o único detentor dos saberes, enquanto o/a paciente assume um papel de passividade frente ao seu processo de saúde-doença (BARROS, 2002). Entretanto, no contexto de uma internação, na qual as acompanhantes são mulheres indígenas,

3 Há vários empregos para a palavra manejo no âmbito da Saúde, no entanto, aqui se refere às situações em que é utilizada por profissionais do Hospital para se reportarem ao diálogo e atendimento aos familiares da população usuária dos serviços de saúde. 
observou-se através da experiência em campo que essa autonomia apresenta-se ainda mais limitada, possivelmente pela barreira da língua e por uma compreensão de saúde que se difere da concepção ocidental.

Nosso intuito com o mapeamento e a análise do discurso científico sobre as mulheres indígenas no campo da saúde, à luz da crítica feminista e dos estudos de gênero, é colaborar com outros elementos para o debate teórico-prático referente à assistência prestada a essas mulheres no âmbito do Sistema Único de Saúde (SUS). A partir desse aporte teórico, construímos a discussão dos resultados valorizando os aspectos subjetivos e culturais.

\section{Procedimentos metodológicos}

Esse estudo de natureza bibliográfica e de abordagem qualitativa foi realizado ao longo de 2017. A técnica de interpretação dos dados seguiu a metodologia da análise de conteúdo, em sua modalidade temática. De acordo com Bardin (1977), a técnica consiste na identificação dos núcleos de sentido presentes nos temas, oriundos da ação de classificação do material que compõe o corpus da pesquisa.

Primeiramente, empreendemos um levantamento na biblioteca online Scientific Eletronic Library Online (SciELO), utilizando os seguintes descritores: saúde das mulheres indígenas; saúde and mulher and indigena; saúde and mulheres and indigenas; etnia and saúde and mulher; etnia and saúde and mulheres. Aplicamos o operador booleano and com a finalidade de ampliar os resultados da nossa busca. A fim de orientar a composição do corpus, elencamos os seguintes critérios de inclusão: 1) estudos que retratam a realidade brasileira; 2) título e texto com idioma em português; 3) textos necessariamente publicados em periódicos do campo da saúde; 4) enfoque na saúde sexual e saúde reprodutiva.

Nesse levantamento, encontramos 211 referências, sendo que 67 dessas tratavam-se de artigos duplicados, prontamente excluídos da pesquisa. Através da leitura dos títulos e dos resumos, selecionamos 21 referências que, a priori, encontravam-se de acordo com os critérios de inclusão estabelecidos.

Posteriormente, os textos: "Saúde reprodutiva e mulheres indígenas do Alto Rio Negro", de autoria da cientista social e demógrafa Marta Azevedo; "O saber 
Kaiamurá sobre a saúde do corpo", da etnóloga Carmem Junqueira e da cientista social Heloisa Pagliaro; "Fecundidade e saúde reprodutiva das mulheres Suyá (Kidsêdjê): aspectos demográficos e culturais", de Heloisa Pagliaro em parceria com a médica Sofia Mendonça e o médico Roberto Baruzzi, todos os artigos publicados no periódico "Caderno CRH" (revista de Ciências Sociais do Centro de Estudos e Pesquisas em Humanidades da Universidade Federal da Bahia), foram excluídos da pesquisa, por não se tratarem de publicações realizadas em periódicos do campo da saúde, alvo de nosso estudo.

Após a realização da leitura flutuante, também foram excluídos os textos "Atenção em saúde reprodutiva no Brasil: eventuais diferenciais étnicoraciais"; "Criminalização do aborto no Brasil e implicações à saúde pública"; "Incontinência urinária em mulheres que buscam exame preventivo de câncer de colo uterino: fatores sociodemográficos e comportamentais"; "Utilização de métodos contraceptivos entre as usuárias da rede pública de saúde do município de Maringá-PR"; "Violência sexual por parceiro íntimo entre homens e mulheres no Brasil urbano, 2005". Ao ler os artigos, percebemos que as/os autoras/autores compreendem as categorias etnia e raça como equivalentes, nesse sentido, utilizam a categoria etnia para se referirem não à população indigena, mas à negra, não havendo menção às mulheres indigenas nas estruturas textuais. $\bigcirc$ texto "Reprodução: o desafio feminista para uma política social" foi igualmente excluído, pois trabalhava a categoria reprodução a partir de uma concepção do cuidado do lar, desvinculando-a da saúde sexual e saúde reprodutiva.

Sendo assim, permaneceram para análise 11 artigos, dispostos no quadro a seguir: 
Quadro 1. Quantitativo de artigos selecionados

\begin{tabular}{|c|c|c|c|c|c|}
\hline Texto & Titulo do artigo & Autoria & Deseritor & Periódico & Ano* \\
\hline 01 & $\begin{array}{l}\text { Processo de gestar e parir entre as mulheres } \\
\text { Kaingang }\end{array}$ & $\begin{array}{l}\text { MOLITERNO, } \\
\text { Aline Cardoso } \\
\text { Machado et al. }\end{array}$ & $\begin{array}{l}\text { Saúde da } \\
\text { Mulher } \\
\text { Indigena }\end{array}$ & $\begin{array}{c}\text { Texto \& } \\
\text { Contexto } \\
\text { Enfermagem }\end{array}$ & 2013 \\
\hline 02 & $\begin{array}{l}\text { Exploraçào de fatores de risco para câneer } \\
\text { de mama em mulheres de etnia Kaingáng, } \\
\text { Terra Indigena Faxinal, Paraná, Brasil, } \\
2008\end{array}$ & $\begin{array}{l}\text { SILVA, Edimara } \\
\text { Patricia da et } a l .\end{array}$ & $\begin{array}{l}\text { Saúde da } \\
\text { Mulher } \\
\text { Indigena }\end{array}$ & $\begin{array}{l}\text { Cadernos de } \\
\text { Saúde Pública }\end{array}$ & 2008 \\
\hline 03 & $\begin{array}{l}\text { Equidade inversa e desigualdades no acesso } \\
\text { à tecnologia no parto } \mathrm{em} \text { Santa Catarina, } \\
\text { Brasil, } 2000 \text { a } 2004\end{array}$ & $\begin{array}{l}\text { SOUZA JUNIOR, } \\
\text { Júlio Cesar de et } \\
\text { al. }\end{array}$ & $\begin{array}{l}\text { Saúde da } \\
\text { Mulher } \\
\text { Indigena }\end{array}$ & $\begin{array}{c}\text { Revista } \\
\text { Brasileira de } \\
\text { Saude Materno } \\
\text { Infantil }\end{array}$ & 2007 \\
\hline 04 & $\begin{array}{l}\text { Recuperação populacional e fecundidade } \\
\text { dos Kamaiurá, povo Tupi do Alto Xingu, } \\
\text { Brasil Central, 1970-2003 }\end{array}$ & $\begin{array}{l}\text { PAGLIARO, } \\
\text { Heloisa; } \\
\text { JUNQUEIRA, } \\
\text { Carmem. }\end{array}$ & $\begin{array}{l}\text { Saúde da } \\
\text { Mulher } \\
\text { Indigena }\end{array}$ & $\begin{array}{l}\text { Saúde \& } \\
\text { Sociedade }\end{array}$ & 2007 \\
\hline 05 & Pesquisa Nacional de Aborto 2016 & $\begin{array}{c}\text { DINIZ, Débora et } \\
\text { al. }\end{array}$ & $\begin{array}{l}\text { Saúde das } \\
\text { Mulheres } \\
\text { Indigenas }\end{array}$ & $\begin{array}{c}\text { Ciência \& } \\
\text { Saúde Coletiva }\end{array}$ & 2017 \\
\hline 06 & $\begin{array}{l}\text { Mortalidade por câncer de mama feminino } \\
\text { no Brasil de acordo com a cor }\end{array}$ & $\begin{array}{c}\text { SOARES, } \\
\text { Leonardo Ribeiro } \\
\text { et al. }\end{array}$ & $\begin{array}{l}\text { Saúde das } \\
\text { Mulheres } \\
\text { Indigenas }\end{array}$ & $\begin{array}{l}\text { Revista } \\
\text { Brasileira de } \\
\text { Ginecologia e } \\
\text { Obstetricia }\end{array}$ & 2015 \\
\hline 07 & $\begin{array}{l}\text { Prevalência de atipias citológicas e } \\
\text { infecção pelo papilomavirus humano de } \\
\text { alto risco em mulheres indigenas Panará, } \\
\text { povo indigena do Brasil Central }\end{array}$ & $\begin{array}{l}\text { RODRIGUES, } \\
\text { Douglas Antonio } \\
\text { et al. }\end{array}$ & $\begin{array}{l}\text { Saúde das } \\
\text { Mulheres } \\
\text { Indigenas }\end{array}$ & $\begin{array}{l}\text { Cadernos de } \\
\text { Saúde Pública }\end{array}$ & 2014 \\
\hline 08 & $\begin{array}{l}\text { Prevalêneia de sifilis na gestação e } \\
\text { testagem pré-natal: Estudo Nascer no Brasil }\end{array}$ & $\begin{array}{l}\text { DOMINGUES, } \\
\text { Rosa Maria } \\
\text { Soares et al. }\end{array}$ & $\begin{array}{l}\text { Saúde das } \\
\text { Mulheres } \\
\text { Indigenas }\end{array}$ & $\begin{array}{c}\text { Revista de } \\
\text { Saúde Pública }\end{array}$ & 2014 \\
\hline 09 & $\begin{array}{l}\text { Mortalidade materna e sua interface com a } \\
\text { raça em Mato Grosso }\end{array}$ & $\begin{array}{c}\text { TEIXEIRA, } \\
\text { Neuma } \\
\text { Zamariano Fanaia } \\
\text { et al. }\end{array}$ & $\begin{array}{l}\text { Saúde das } \\
\text { Mulheres } \\
\text { Indigenas }\end{array}$ & $\begin{array}{c}\text { Revista } \\
\text { Brasileira de } \\
\text { Saúde Materno } \\
\text { Infantil }\end{array}$ & 2012 \\
\hline 10 & $\begin{array}{l}\text { Fecundidade das mulheres autodeclaradas } \\
\text { indigenas residentes em Minas Gerais, } \\
\text { Brasil: uma análise a partir do Censo } \\
\text { Demográfico } 2000\end{array}$ & $\begin{array}{l}\text { DIAS JÚNIOR, } \\
\text { Claudia Santiago } \\
\text { et al. }\end{array}$ & $\begin{array}{l}\text { Saúde das } \\
\text { Mulheres } \\
\text { Indigenas }\end{array}$ & $\begin{array}{l}\text { Cadernos de } \\
\text { Saúde Pública }\end{array}$ & 2008 \\
\hline 11 & $\begin{array}{l}\text { Fatores de risco para câncer de mama } \mathrm{em} \\
\text { mulheres indigenas Teréna de área rural, } \\
\text { Estado do Mato Grosso do Sul, Brasil }\end{array}$ & $\begin{array}{l}\text { LIMA, Marilana } \\
\text { Geimba de et al. }\end{array}$ & $\begin{array}{l}\text { Saude das } \\
\text { Mulheres } \\
\text { Indigenas }\end{array}$ & $\begin{array}{l}\text { Cadernos de } \\
\text { Saúde Pública }\end{array}$ & 2001 \\
\hline
\end{tabular}

Fonte: Elaborado pelas autoras (2017). ${ }^{*}$ Refere-se ao ano de publicação no periódico.

Após a realização da leitura transversal, os textos foram agrupados em dois blocos temáticos: 1) Raça/etnia como sinônimos: implicações para o campo da Saúde; e 2) Representação das mulheres indígenas nas revistas de saúde. 


\section{Raça/etnia como sinônimos: implicações para o campo da Saúde}

Os textos compilados neste bloco temático tratam de estudos referentes a problemas de saúde pública que acometem as mulheres no Brasil, tais como: aborto; mortalidade materna; mortalidade por câncer de mama; sífilis na gestação entre outros. A categoria indígena aparece nesses textos como um marcador social da diferença, sem um aprofundamento a respeito das experiências de vida das mulheres indígenas em específico, impossibilitando a realização de uma análise referente à forma como essas mulheres estão representadas. Ademais, a leitura transversal desses textos identificou uma tendência à compreensão das categorias raça e etnia como univocas, questão que abordaremos nesse tópico.

O texto 03, intitulado "Equidade inversa e desigualdades no acesso à tecnologia no parto em Santa Catarina, Brasil, 2000 a 2004", logo no resumo que aponta as variáveis analisadas no estudo, apresenta a apreensão de etnia como referente à cor da pele. No texto 05, denominado "Pesquisa Nacional de Aborto 2016", encontramos na tabela 1, localizada na página 657, a categoria indígena na variável "raça", juntamente com as categorias branca, preta, parda e amarela, as mesmas categorias utilizadas na classificação "cor ou raça" do Instituto Brasileiro de Geografia e Estatística (IBGE).

No texto 06, "Mortalidade por câncer de mama feminino no Brasil de acordo com a cor", como o título indica, é empregada a variável "cor". Ao longo do artigo, é possivel identificar emprego da categoria etnia como referente à raça, como podemos observar no seguinte trecho: "A população brasileira, composta por várias etnias (brancas, negras e indigenas), apresenta variações geográficas significativas e constitui a quinta maior população mundial" (SOARES, 2015, p. 391).

Em "Prevalência de síflis na gestação e testagem pré-natal: Estudo Nascer no Brasil", oitavo texto de nosso corpus, as autoras e o autor utilizam "cor da pele auto referida (branca; preta; parda; amarela; indígena)" (DOMINGUES, 2014, p. 768). Novamente, as categorias utilizadas são as mesmas da classificação do IBGE: "cor ou raça". Nesse horizonte, questionamos a possibilidade desses textos se nortearem pela tipologia adotada pelo IBGE.

Deste modo, no texto 09, nomeado "Mortalidade materna e sua interface 
com a raça em Mato Grosso", em seu item "métodos", as autoras explicitam que a caracterização de raça/cor utilizada foi determinada segundo a classificação do IBGE, reforçando a suspeita levantada. Procuramos, portanto, entender os sentidos dados pelo IBGE à categoria raça e etnia.

No documento "Características Étnico-raciais da população: classificações e identidades", o IBGE apresenta um compilado de textos referentes à classificação de cor ou raça, oriunda da Pesquisa das Características Étnico-Raciais da População (PCERP), de 2008. Sua intenção era “(...) compreender melhor o atual sistema de classificação da cor ou raça nas pesquisas domiciliares realizadas pela Instituição e contribuir para o seu aprimoramento" (IBGE, 2013, s/n). Realizamos breve leitura dos textos trazidos nesse documento e, em Petruccelli (2013), encontramos as seguintes considerações sobre a categoria raça:

Assim, hoje há amplo consenso de sua ineficácia teórica como conceito biológico, tendo sido definitivamente erradicado pela genética, mas, ao mesmo tempo, multiplicam-se as constatações de sua persistência como realidade simbólica extremamente eficaz nos seus efeitos sociais. Com efeito, sua força é precisamente verificada pelo fato de que este conceito se apoia sobre uma marca "natural", visível, transmissivel de maneira hereditária, pregnante à percepção imediata, dando a possibilidade, assim, de gerar grupos sociais reais ou categorias que podem ser qualificadas como raciais (Bonniol, 1992b). Dessa maneira, a noção de raça ainda permeia o conjunto de relações sociais, atravessa práticas e crenças e determina o lugar e o status de indivíduos e grupos na sociedade. Nesse sentido, a pessoa pode ser identificada, classificada, hierarquizada, priorizada ou subalternizada a partir de uma cor/raça/etnia ou origem a ela atribuída por quem a observa. Deve-se ter os devidos cuidados nessa discussão sobre o que define o pertencimento - por exemplo, quem é índio? (PETRUCCELLI, 2013, s/n).

Apesar de o autor levantar o questionamento referente ao "indio" não há um entendimento de diferenciação entre os conceitos de raça e etnia, nem uma exposição acerca das especificidades culturais postas pela questão indígena. Desse modo, o texto segue apresentando raça como uma categoria socialmente construída. Conforme Petruccelli (2013), a classificação racial no Brasil é uma prática desenvolvida desde a época da escravidão, quando, através 
de descrições de traços físicos (fenótipos), os donos de pessoas escravizadas publicavam cartazes de busca, na ocasião de fugas.

Em 1872, as estatísticas públicas do primeiro recenseamento categorizavam a população em: branco, preto, pardo e caboclo, trazendo a ideia das misturas étnico-raciais enquanto categoria. Anos depois, no Censo Demográfico de 1940, houve uma mudança radical dessa definição, valorizando a "cor" em detrimento da origem étnico-racial, passando a classificação a ser: branco, pardo, preto e amarelo (PETRUCCELLI apud CAMARGO, 2013). Segundo Petruccelli (2013), é apenas em 1991 que a categoria indígena é reintroduzida na classificação, sendo qualificada como raça, e a pergunta para auto identificação racial torna-se "cor ou raça".

Conforme explicitado, o documento do IBGE situa, de maneira geral, como - processo de miscigenação influenciou a construção da identidade da sociedade brasileira, fazendo com que os conceitos de raça, etnia e cor fossem vistos de maneira entrelaçadas. Esse entendimento, como apresentado no levantamento e análise dos textos, tem refletido na produção científica no campo da saúde sobre a população indígena.

Nesse horizonte, Moubarac (2013) aponta que uma das grandes falhas dos pesquisadores das áreas epidemiológica e da saúde pública é justamente utilizar raça e etnia como sinônimos. A partir de uma perspectiva sociocultural, o antropólogo explica que ambas são construtos sociais. Enquanto raça foi um conceito biológico baseado em questões morfológicas, geográficas e marcas genéticas - refutado pela própria genética, que ainda determina experiências de discriminação e de opressão baseadas em estereótipos - a etnia se constituiu como um conceito construído através da noção de compartilhamento, nascido das relações sociais e baseado em crenças ancestrais comuns. Assim, a categoria etnia traz em si a noção de diversidade humana, ou seja, de grupos que se distinguem e se organizam a partir de uma cosmovisão outra, que não a ocidental.

A importância de diferenciar as categorias decorre do fato de que se raça e etnia são marcadores sociais que indicam subalternidade no sistema hegemônico, as opressões experimentadas pelos grupos marcados por questões étnicas e 
raciais se dão de formas distintas. Se a população negra, ainda que precariamente, está inserida na cosmovisão ocidental, a população indígena se apresenta (mesmo com a diversidade de etnias e de situações de inserção na cultura do ocidente) à margem da sociedade ocidental. Pensando no campo da saúde, por exemplo, isso significa que o próprio contato cultural com as tecnologias de saúde ocidentais pode representar uma forma de opressão, na medida em que, no exemplo trazido aqui, medicalizar e tentar engendrar os corpos de mulheres inseridas em outros contextos socioculturais nos padrões de assistência ocidentais podem invisibilizar suas experiências de vida e normatizar suas concepções e vivências de saúde.

Sendo assim, nos questionamos sobre os desdobramentos teóricos e práticos da concepção de etnia e raça como similares. É possível que essa visão comprometa o acesso das etnias indígenas aos serviços públicos em geral e, principalmente, aos serviços de saúde. A falta de compreensão no tocante às especificidades dessa população tem resultado em um enquadramento da concepção de saúde-doença ocidental, o que aos poucos vêm apagando as vivencias de saúde inerente às diferentes culturas. Essa compreensão univoca de raça-etnia poderia limitar o olhar frente a essa população, visto que as opressões de raça e etnia se diferem em essência.

\section{Representação das mulheres indígenas nas revistas de saúde}

Haraway (1995) e Harding (1993 e 2002) apontam a importância de se pensar metodologias de pesquisa que favoreçam as falas das próprias mulheres sobre suas realidades de vida e, para tanto, utilizam a categoria experiência. Para Haraway (1995), a ciência não é neutra, nem objetiva e foi construída a partir da visão dos homens, logo, "Masculinistas", invisibilizando a existência das mulheres. Nesse sentido, experiência é um recurso para projetar a realidade das mulheres, mas, sobretudo, suas subjetividades. Permite, assim, que emerjam suas especificidades em detrimento da ideia de universalidade da ciência moderna.

Louro (1996) argumenta na mesma direção de Haraway ao afirmar que é preciso atentarmos para o fato de que uma ciência que se pretende universal corre o risco de reproduzir discursos de dominação de gênero, coloniais, raciais e étnicas. Segundo a autora, "uma reflexão mais cuidadosa deve (...) reconhecer, então, que as categorizações universais sempre são excludentes, legitimando os 
já legitimados e colocando à margem aqueles (as) que não se 'enquadram' em suas referências" (LOURO, 1996, p. 15).

Nesse bloco temático, ancoradas nas contribuições das estudiosas feministas citadas, apresentamos as metodologias utilizadas nos estudos e suas implicações para a representação das mulheres indígenas e de seus aspectos subjetivos. A partir de tal opção analítica, foi possivel perceber se nos artigos há uma valorização das experiências das mulheres indígenas e de seu local de fala, bem como se o debate do campo da saúde tem como centralidade a realidade epidemiológica. Para dar visibilidade à discussão, construímos dois subblocos temáticos denominados: 1) textos que utilizam métodos qualitativos e epidemiológicos; 2) textos que trabalham a partir de dados estatísticos.

\section{Textos que utilizam métodos qualitativos e epidemiológicos}

Nos artigos 01 - "Processo de gestar e parir entre as mulheres Kaingang"; 02 - "Exploração de fatores de risco para câncer de mama em mulheres de etnia Kaingáng, Terra Indígena Faxinal, Paraná, Brasil; 11 - "Fatores de risco para câncer de mama em mulheres indígenas Teréna de área rural, Estado de Mato Grosso do Sul, Brasil", há uma predominância de procedimentos metodológicos com foco na fala das mulheres indígenas. No texto 01 , as autoras realizaram a coleta de dados por meio da observação participante, grupos focais e entrevistas semiestruturadas. Os demais textos, que se aproximam devido à temática dos fatores de risco para o câncer de mama, utilizaram entrevistas estruturadas.

O texto 01, como o título sugere, tem como objetivo identificar o processo de gestar e parir entre as mulheres Kaingang. A autoria é partilhada por três autoras da área da enfermagem, uma da educação e uma da saúde pública. $\bigcirc$ artigo destaca-se por ser o único de nosso corpus a apresentar uma pesquisa qualitativa de abordagem etnográfica. Historicamente, a etnografia é uma metodologia muito presente nas pesquisas e estudos da área da antropologia (EVANSPRITCHARD, 1993; MALINOWSKI, 1976).

As autoras se apoiam nessa abordagem a fim de apreenderem a cosmologia da população estudada. Através das entrevistas semiestruturadas e do grupo focal, puderam identificar que um número relevante de mulheres que participaram da 
pesquisa tiveram experiências ruins no momento do trabalho de parto, em âmbito hospitalar. As autoras lançaram mão do auxilio de um intérprete bilíngue para a realização de entrevistas com as mulheres indígenas, uma vez que as entrevistadas não falavam português.

Destaca-se o empenho das mesmas em conhecer o contexto no qual as mulheres viviam, reconhecendo suas experiências de vida, a fim de representá-las de maneira mais próxima possivel. Este movimento ficou evidente na forma como construíram o processo de análise dos dados, construindo-o de modo "circular", ou seja, a análise foi realizada concomitante à fase da coleta de dados. A partir das inferências realizadas, as autoras retornavam às participantes "e informanteschave para sua validação, buscando assim dados que pudessem confirmar, refutar ou complementar cada uma delas" (MOLITERNO et al., 2013, p. 295).

texto 02 e o texto 11 utilizaram métodos de estudos epidemiológicos, sendo o texto 02 caracterizado por um estudo transversal descritivo e exploratório e o texto 11 apresenta a realização de dois inquéritos com questionário padronizado, um realizado com 330 mulheres, no ano de 1995, e outro com 40 mulheres, em 1997. Ambos os textos (02 e 11) buscaram conhecer os padrões de vida reprodutiva, rotina alimentar, histórico de doenças pessoais e de familiares das mulheres indígenas. $\mathrm{O}$ texto 02 , ainda, colheu informações referentes ao perfil sócio demográfico, a partir de indicadores, como: renda; escolaridade; estado civil; compreensão concernente à neoplasia mamária. Referente aos fatores de risco, o mesmo texto contemplou variáveis, como: tempo de aleitamento materno; uso de anticoncepcionais; terapias de reposição hormonal; sedentarismo; tabagismo; ingestão alcoólica. $\bigcirc$ texto 11 também realizou levantamento do índice de massa corporal (IMC). Destaca-se que o texto 02, assim como os textos compilados no bloco anterior, também apresenta o entendimento de raça e etnia como sinônimos.

Como apontamos, os referidos textos tratam de estudos epidemiológicos, voltados para a análise de dados estatísticos e possuem como instrumento de coleta de dados as entrevistas estruturadas. Ainda que estruturadas, acreditamos que a realização de entrevistas com as mulheres indígenas é de suma importância, 
pois caracteriza um processo de escuta sobre elementos de suas realidades e não dados retirados de registros realizados por terceiros. Todavia, é importante salientar que a utilização de entrevistas fechadas pode dificultar que subjetividades emerjam. Uma das limitações de tal técnica de investigação é a impossibilidade de aprofundar os dados subjetivos que não estão contidos nas perguntas previamente desenvolvidas. Levanta-se, com isso, o questionamento: quais outros dados poderiam aparecer em pesquisas sobre fatores de risco para câncer de mama, caso as autoras e os autores dos demais textos tivessem optado por procedimentos metodológicos que favorecessem a apreensão do discurso nativo?

Acreditamos que os resultados do texto 01 podem contribuir para repensar a cultura da "medicina da mulher" (ROHDEN, 2001) e avançar nas discussões da saúde e dos direitos sexuais e reprodutivos (ÁVILA, 2003; CORRÊA, 2009; WICHTERICH, 2015), assim como do processo de melhoria da assistência oferecida às mulheres indígenas no âmbito dos hospitais vinculados ao Sistema Único de Saúde (SUS). A partir dos relatos das informantes, o estudo aponta que as mulheres Kaingang acabam sendo impedidas de parir acocoradas - posição através da qual mulheres de sua etnia são acostumadas a parir. Ademais, a obrigação de que permaneçam em posição litotômica ${ }^{4}$ não deveria mais fazer parte do cotidiano do parto hospitalar, pois não se encontra de acordo com as indicações das normativas do Ministério da Saúde, informação devidamente pontuada pelas autoras supracitadas.

\section{Textos que trabalham a partir de dados estatísticos}

Como apontamos anteriormente, os textos compilados neste sub-bloco se referem a estudos realizados com dados estatísticos, seja de censo demográfico, como é o caso do texto 10 - "Fecundidade das mulheres autodeclaradas indígenas residentes em Minas Gerais, Brasil: uma análise a partir do Censo Demográfico 2000", ou de registro de programa de saúde, como é o texto 04 - "Recuperação Populacional e fecundidade dos Kamaiurá, povo Tupi do Alto Xingu, Brasil Central, 1970-2003".

No texto 10, inclusive, não há uma aproximação com uma etnia em específico, 
devido à utilização de dados provenientes do Censo Demográfico. Tal fato impossibilita que características mais subjetivas sejam obtidas e discutidas à luz da leitura teórica adotada nesse artigo. Somam-se a isso, os limites que os dados estatísticos impõem à visualização de elementos subjetivos, por não estarem no escopo do artigo, como evidente nos seguintes trechos:

[...] Este trabalho utiliza dados do Censo Demográfico 2000 para descrever e comparar a estrutura e o nivel da fecundidade de periodo e coorte das mulheres autodeclaradas indígenas residentes em Minas Gerais, Brasil (DIAS JÚNIOR, 2008, p. 2477).

Finalmente, é importante mencionar que os dados de Minas Gerais não permitem verificar diretamente o comportamento reprodutivo das mulheres indígenas aldeadas, e por conseqüência, por etnia. Eles permitem apenas sugerir que o comportamento observado entre as mulheres indigenas residentes nas áreas rurais com Terras Indígenas seja uma aproximação do comportamento das mulheres aldeadas. De qualquer forma, pode-se inferir que, apesar de alta, a fecundidade nas Terras Indígenas de Minas Gerais já começou a experimentar um processo de declínio (IDEM, p. 2484).

O texto 07 - "Prevalência de atipias citológicas e infecção pelo papilomavírus humano de alto risco em mulheres indígenas Panará, povo indígena do Brasil Central", por sua vez, versa sobre um estudo observacional transversal, realizado com dados provenientes dos resultados de exames ginecológicos. De acordo com o texto, foram explicitados às mulheres participantes quais os procedimentos que seriam realizados, bem como a relevância do estudo.

O texto 04 não pretende falar especificamente das mulheres Kamaiurá, mas sim de aspectos vivenciados por essa etnia, que de alguma maneira influenciaram seu padrão de fecundidade e comportamento reprodutivo. Nesse horizonte, o trabalho apresenta aspectos culturais do povo Kamaiurá, língua falada, região que habitam, entre outros dados. É possivel identificar uma visibilidade étnica no decorrer do texto, porém, não há um interesse em projetar, especificamente, as experiências das mulheres Kamaiurá.

Nesse contexto, buscando contribuir para a ampliação dos conhecimentos 
no campo da demografia indígena no Brasil e pressupondo que o processo de recuperação demográfica dos Kamaiurá tenha sido gerado também por mudanças em seu comportamento reprodutivo, este trabalho tem o objetivo de identificar modificações no padrão de fecundidade desse povo, nas três décadas que separam a realização do primeiro estudo desse tipo, em 1971, por Camargo e col. (2005), considerando aspectos da sua organização social que intermediariam o comportamento reprodutivo (PAGLIARO, 2007, p. 40).

Ainda no tocante aos fatores que ensejaram modificações no padrão de família dos Kamaiurá, é importante considerar, como referido por Junqueira (1978), um aspecto particularmente significativo da dinâmica populacional desse povo, que diz respeito ao nível de racionalidade com que entendem o processo reprodutivo. $O$ conhecimento e uso de práticas tradicionais de controle da natalidade, incluindo o aborto e o infanticídio, são exemplos dessa racionalidade (IDEM, p. 40).

Cabe destacar o expressivo número de trabalhos epidemiológicos, de modo geral, levantados no transcorrer de nossa pesquisa. Entendemos a importância desse tipo de estudo para se conhecer os padrões das necessidades de saúde dos povos indígenas, bem como a pertinência de dados quantitativos para a construção de políticas de atenção à saúde sexual e reprodutiva. No entanto, partindo da crítica feminista (HARAWAY, 1995; HARDING, 1993, 2002), projeta-se a importância dos elementos qualitativos para a construção de políticas públicas que tratem as mulheres em sua integralidade, conforme preconiza a própria PNAISM.

\section{Considerações finais}

A discussão dos resultados revelou a precariedade das produções científicas acerca da saúde sexual e reprodutiva da mulher indígena no campo da saúde. A escassez de trabalhos publicados, mesmo os exclusivamente epidemiológicos, chama a atenção e ganha relevância acadêmica pois revela o modus operandi das Ciências da Saúde. Por um lado, a falta demonstra a limitação da área em incorporar e traduzir realidades diferentes e diferenciadas. Ainda que haja o reconhecimento das demandas de saúde da mulher indigena e de suas particularidades através da Política Nacional de Atenção à Saúde dos Povos Indígenas, de 2002, essas ainda 
não figuram como objetos de estudos privilegiados no âmbito das Ciências da Saúde. Por outro, a invisibilização das especificidades das mulheres indígenas nas produções científicas na área da saúde corrobora com a crítica já enunciada das teóricas feministas: é necessária uma renovação científica que permita ampliar e complexificar o olhar sobre as opressões múltiplas que criam condições de desigualdade em contextos específicos.

Nesse sentido, se a hipótese que nos guiava era a ausência de discussões que compreendessem uma perspectiva de gênero, ou que valorizassem aspectos subjetivos e culturais referentes à saúde das mulheres indígenas (o que foi comprovado), não julgamos a subalternidade do tema no interior dos estudos epidemiológicos. Consideramos que os elementos evidenciados afetam não só o debate sobre o tema, mas, sobretudo, a prática cotidiana no interior das instituições de saúde pública, posto que a teoria tende a nortear as práticas de atuação.

Outro fator de destaque foi o recorrente entendimento de raça e etnia como sinônimos. A prevalência dessa leitura nas áreas epidemiológica e da saúde pública encobre as opressões vivenciadas pelos grupos étnicos e raciais, que se dão de forma distintas. A compreensão que remete à similitude das categorias pode limitar o acesso da população indígena aos serviços de saúde e impossibilitar uma assistência que considere suas dimensões singulares, valores, crenças e modos de ser, essenciais para a produção e manutenção de sua saúde.

No tocante à questão do debate de gênero nos trabalhos sobre a saúde sexual e saúde reprodutiva das mulheres indígenas, suas narrativas ainda são reproduzidas, em grande maioria, de maneira vertical, ou seja, as/os pesquisadoras/ es falando sobre elas e não com elas. Em uma perspectiva feminista, as mulheres indígenas permanecem invisibilizadas até mesmo nas discussões nas quais são referidas. Enxergadas apenas como objetos e não como sujeitas, compõem dados estatísticos que não traduzem as particularidades de suas existências. Como consequência, se mantém constante a universalização de experiências das mulheres e o apagamento de existências outras, como as das mulheres indígenas, acarretando a ratificação dos sistemas de opressão existentes.

Por fim, a inclusão de debates referentes à saúde das mulheres indígenas 
(tanto através dos epidemiológicos, quanto dos voltados para saúde pública), com o intuito de qualificar os serviços oferecidos às mulheres indígenas, apresentouse embrionária, para não afirmar incipiente, embora necessária e em processo. Ensejamos que os dados trazidos à cena possam contribuir para a construção de debates teórico-práticos mais diversificados no campo da saúde.

Referências

ÁVILA, M. B. Direitos sexuais e reprodutivos: desafios para as políticas de saúde. Cad. Saúde Pública. Rio de Janeiro, 19(Sup.2), p. 465-469, 2003.

BARDIN, L. Análise de conteúdo. Lisboa: Persona, 1977.

BARROS, José Augusto C. Pensando o processo saúde doença: a que responde o modelo biomédico? Saúde e Sociedade. São Paulo, 11, p. 67-84, 2002.

BRASIL. Ministério da Saúde. Política Nacional de Atenção Integral à Saúde da Mulher: princípios e diretrizes. Brasilia: Ministério da Saúde, 2004.

CARAPINHEIRO, Graça. Saberes e poderes no hospital: uma sociologia dos serviços hospitalares. Porto (POR): Edições Afrontamento, 1988.

CORRÊA, Sonia. O percurso global dos direitos sexuais: entre "margens" e "centros". Bagoas. Rio Grande do Norte, n. 4, p. 17-42, 2009.

DIAS JÚNIOR, Cláudio Santiago et al. Fecundidade das mulheres autodeclaradas indígenas residentes em Minas Gerais, Brasil: uma análise a partir do Censo Demográfico 2000. Cadernos de Saúde Pública, Rio de Janeiro, vol. 24 n. 11, p. 2477-2486, Nov. 2008. Disponivel em: http:// dx.doi.org/10.1590/S0102-311X2008001100003 Acesso em: 11/09/2017.

DINIZ, Debora; MEDEIROS, Marcelo; MADEIRO, Alberto. Pesquisa Nacional de Aborto 2016. Revista Ciência \& Saúde Coletiva, Rio de Janeiro, vol. 22 n. 2, p. 653-660, Feb. 2017.

DOMINGUES, Rosa Maria Soares Madeira et al. Prevalência de sífilis na gestação e testagem pré-natal: Estudo Nascer no Brasil. Revista de Saúde Pública, São Paulo, vol. 48, n. 5, p. 766-774, Oct. 2014.

EVANS-PRITCHARD, E.E. Os Nuer: uma descrição dos modos de subsistência e das instituições políticas de um povo nilota. São Paulo: Perspectiva, 1993.

HARAWAY, Donna. SABERES LOCALIZADOS: a questão da ciência para - feminismo e o privilégio da perspectiva parcial. In: Cadernos Pagu. (5), p. 7-41. Campinas: Unicamp, 1995.

HARDING, Sandra. Existe un método feminista? Tradução de Gloria 
Helena Bernal. In: BARTRA, Eli (org.). Debates em torno a um metodologia feminista. $2^{a}$ Edição, p. 09-34. México/DF: UNAM, 2002,

A instabilidade das categorias analíticas na teoria feminista. Revista Estudos Feministas, vol. I, n 10 p.7-32. Florianópolis: UFSC, 1993.

HYGINO, Angela Maria. As regras institucionais e os espaços para negociação: a negociação da ordem hospitalar entre profissionais de saúde e usuários de um serviço público de pediatria. In: LISBOA, Teresa Kleba et al. (org.). Estudos Interdisciplinares sobre Gênero, Família e Saúde. p. 317-341. Tubarão: Copiart, 2017.

INSTITUTO BRASILEIRO DE GEOGRAFIA E ESTATÍSTICA (IBGE). Características Étnico-raciais da População classificações e identidades. Estudos e Análises Informação Demográfica e Socioeconômica. Rio de Janeiro: IBGE, 2013.

LIMA, Marilana Geimba de et al. Fatores de risco para câncer de mama em mulheres indígenas Teréna de área rural, Estado do Mato Grosso do Sul, Brasil. Cadernos de Saúde Pública, Rio de Janeiro, vol. 17, n. 6, p. 15371544, Nov./Dec. 2001. Disponivel em: http://dx.doi.org/10.1590/S0102311X2001000600026 Acesso em: 12/09/2017.

LOURO, G. L. Nas redes do conceito de gênero. In: LOPES, Marta Julia Marques; MEYER, Dagmar Estermann; WALDOW, Vera Regina (orgs). Gênero e Saúde. Porto Ảlegre: Artes Médicas, 1996.

MALINOWSKI, B. Argonautas do Pacífico Ocidental. Coleção "Os pensadores". São Paulo: Ábril Cultural, 1976.

MOLITERNO, Aline Cardoso Machado et al. Processo de gestar e parir entre as mulheres Kaingang. Revista Texto \& Contexto - Enfermagem, Florianópolis. Vol. 22, n. 2, p. 293-301, Jun. 2013. Disponivel em: http:// www.scielo.br/pdf/tce/v22n2/v22n2a04.pdf Acesso em: 08/09/2017.

MOUBARAC, Jean-Claude. Persisting problems related to race and ethnicity in public health and epidemiology research. Revista de Saúde Pública, vol.47 no.1 São Paulo fev. 2013. Disponível em: http://dx.doi. org/10.1590/S0034-89102013000100014. Acesso em: 06/12/2017.

PAGLIARO, Heloisa; JUNQUEIRA, Carmen. Recuperação populacional e fecundidade dos Kamaiurá, povo Tupi do Alto Xingu, Brasil Central, 19702003. Revista Saúde \& Sociedade, São Paulo, vol. 16, n. 2, p. 37-47, May/Aug. 2007. Disponivel em: http://www.scielo.br/pdf/sausoc/v16n2/05.pdf Acesso em: 10/09/2017.

PETRUCCELLI, J. L. Raça, identidade, identificação: abordagem histórica conceitual. In: INSTITUTO BRASILEIRO DE GEOGRAFIA E ESTATÍSTICA (IBGE). Características Étnico-raciais da População classificações e identidades. Estudos e Análises Informação Demográfica e 
Socioeconômica. Rio de Janeiro: IBGE, 2013.

RODRIGUES, Douglas Antonio et al. Prevalência de atipias citológicas e infecção pelo papilomavírus humano de alto risco em mulheres indígenas Panará, povo indígena do Brasil Central. Cadernos de Saúde Pública, Rio de Janeiro, vol. 30, n.12, p. 2587-2593, Dec. 2014. Disponivel em: http://www.scielo.br/pdf/csp/v30n12/0102-311X-csp-30-12-02587.pdf Acesso em: 10/09/2017.

ROHDEN, F. Uma Ciência da Diferença: sexo e gênero na medicina da mulher. Rio de Janeiro: Editora FIOCRUZ, 2001.

SOARES, Leonardo Ribeiro et al. Mortalidade por câncer de mama feminino no Brasil de acordo com a cor. Revista Brasileira de Ginecologia e Obstetrícia, Rio de Janeiro, vol. 37, n. 8, p. 388-392, Aug. 2015.

SOUZA JUNIOR, Julio César de et al. Equidade inversa e desigualdades no acesso à tecnologia no parto em Santa Catarina, Brasil, 2000 a 2004. Revista Brasileira de Saúde Materno Infantil, Recife, vol. 7, n. 4, p. 397-403, Oct./Dec. 2007.

SILVA, Edimara Patricia da et al. Exploração de fatores de risco para câncer de mama em mulheres de etnia Kaingáng, Terra Indígena Faxinal, Paraná, Brasil, 2008. Cadernos de Saúde Pública, Rio de Janeiro, vol. 25 n. 7, p. 14931500, Jul. 2009. Disponivel em: http://www.scielo.br/pdf/csp/v25n7/07.pdf Acesso em: 09/09/2017.

TEIXEIRA, Neuma Zamariano Fanaia et al. Mortalidade materna e sua interface com a raça em Mato Grosso. Revista Brasileira de Saúde Materno Infantil, Recife, vol. 12 n. 1, p. 27-35, Jan./Mar, 2012.

WICHTERICH, C. Direitos Sexuais e Reprodutivos. Rio de Janeiro: Heinrich Böll Foundation, 2015.

Recebido em janeiro de 2018

Aceito para publicação em maio de 2018 